\title{
Sistemas Gerenciadores de Legado Digital: implicações tecnológicas e legais em redes sociais
}

\author{
Cristiano Maciel \\ Instituto de Computação - Universidade Federal de Mato Grosso (UFMT) \\ Cuiabá, MT-Brazil,cmaciel@ufmt.br
}

\begin{abstract}
This informative theoretical essay discusses controversial aspects related to digital legacy management systems by focusing on social networks and presenting technological and legal issues from the perspective of the researchers. We intend to reflect upon how to properly address this theme and amplify the research and the scientific and technological development in this area, especially in Brazil.
\end{abstract}

Resumo. $O$ ensaio em tela é do tipo informativo-teórico e discute aspectos controversos quanto aos sistemas gerenciadores de legado digital, lançando luz sobre as redes sociais e discutindo questões tecnológicas e legais, a partir da visão do pesquisador sobre o tema. Busca-se fomentar a reflexão sobre o devido tratamento à temática, visando ampliar as pesquisas e o desenvolvimento científico e tecnológico nesta área, especialmente no Brasil.

\section{Introdução}

A morte, como fato que norteia a cessação da vida humana, é um tema completo e que, apesar de ser algo inevitável de acontecer, é muitas vezes evitada nas discussões do dia a dia. Ao certo, todos morrerão. Uns antes, outros depois. Vale a jornada e ter a consciência da finitude agrega valor à vida. Ficam as memórias, as obras, as vivências, as produções.... as emoções vividas e seus registros. A materialização destes legados se faz por meio de objetos físicos repassados ao longo de anos em famílias - ou que se perdem e vão habitar outras casas - e/ou por meio de registros, os quais na atualidade são geralmente digitais. Como podemos então destiná-los para terceiros via software!? A priori, a destinação de bens adquiridos por indivíduos ao longo de suas vidas deveria ser feita por meio de testamento. Todavia, todos nossos dados são bens digitais passíveis de testamento? E, nas redes sociais, como isso ocorre?

Imersos na cultura digital em que vivemos, estamos cada vez mais convivendo com questões relacionadas a morte. Com a pandemia no novocoronavirus, o caráter social da morte foi potencializado nas redes sociais. Impossibilitados de prestar as devidas homenagens, muitos familiares e amigos o fizeram via tecnologias (TREVISAN, MACIEL, 2020). Sabe-se que a morte não deixa de ser um negócio lucrativo no capitalismo, havendo toda uma indústria da morte. No mundo digital, tal indústria já vem sendo discutida [OHMAN; FIORI, 2015] e merece atenção.

$\mathrm{Na}$ discussão sobre legados digitais reside uma série de tensionamentos, possibilidades de análise, desafios interdisciplinares e oportunidades para academia e empresas. Ao longo dos tempos, essas temáticas vêm despertando interesses de pesquisadores de diferentes áreas. Não poderia ser diferente em áreas mais tecnológicas, 
que hoje vem produzindo aplicações com vistas a cada vez aproximar e envolver usuários, incorporando elementos da vida social as necessidades de comunicação desses.

No papel de engenheiros de software, é necessário ter em mente que ao possibilitar a instanciação de uma "vida" em um sistema, há que se projetar também a "morte". O falecimento dos usuários tem sido tratado de diferentes formas nas redes sociais. Assim, as identidades geradas na Web, gerenciadas em vida pelos usuários, podem (ou não) ser gerenciadas após a morte do proprietário da conta. Isso depende, entre outros, de como o sistema é projetado e de como o usuário se comporta frente as possíveis configurações dos sistemas.

O projeto Dados Além da Vida, conhecido como DAVI, desde 2011 discute essa temática no contexto brasileiro, fazendo investigações que abarcam diferentes facetas (DAVI, 2021), a saber: sistemas para gerenciar legados digitais; memoriais digitais - em sites, nas redes sociais, em jogos e como serviços ligados à morte; sistemas de mensagens póstumas; imortalidade digital via software; jogos empáticos relacionados ao tema; serviços ligados aos rituais da morte, como velórios e tecnologias em cemitérios; e educação na temática da morte. Na parte final deste texto, algumas estratégias do projeto no campo das tecnologias associadas a morte são descritas.

Muitas destas facetas têm relação com as redes sociais e é importante traçar esta discussão na academia e no mercado. Em 2016, no V Brazilian Workshop on Social Network Analysis and Mining - BraSNAM, evento-satélite do Congresso da Sociedade Brasileira de Computação (SBC), foi realizado um painel com diferentes profissionais para discutir "Legado digital e dados sensíveis - o que podemos e o que não podemos usar?" (SBC, 2016). Na ocasião, questões relacionadas ao Direito, privacidade, mídia digital e negócios foram debatidas com foco em dados sensíveis e legado digital.

Com base na trajetória do DAVI e inspirado nas discussões do BraSNAM é que propomos este ensaio. Um ensaio científico permite ao autor expor suas ideias sobre determinado tema, de forma original, porém sem esgotar o tema, com base em pesquisa referencial, análises e exemplificações (BRITTO, 2009). Para tal, percorre-se o caminho da exploração, avançando em um sentido da temática, situado no tempo e com certa fragmentação (LARROSA, 2003). O ensaio em tela é do tipo informativo-teórico, uma vez que discute aspectos controversos quanto aos Sistemas Gerenciadores de Legado Digital, lançando luz sobre as redes sociais e discutindo questões tecnológicas e legais, a partir da visão do pesquisador sobre o tema. Este divide opiniões, todavia, a morte faz parte da vida e não podemos deixar de nos preocupar com isso nos sistemas computacionais. Espera-se que os leitores consigam refletir sobre o devido tratamento à temática, permitindo ampliar as pesquisas e o desenvolvimento científico e tecnológico nesta área, especialmente em nosso país.

\section{Sistemas Gerenciadores de Legado Digital}

Os Sistemas Gerenciadores de Legado Digital (SGLD) têm sido discutidos sob diferentes óticas. Por meio de uma revisão não sistemática de literatura, Yamauchi et al. (2021) identificaram quatro abordagens para o estudo de SGLDs: (1) estudo das funcionalidades de um SGDL (GULLOTA et al., 2016) (UEDA et al., 2018), (2) discussão de aspectos relacionados ao tratamento dos dados de um SGDL (BAHRI et al.; 2015), (3) serviços oferecidos por um SGDL (OLIVEIRA et al., 2016) (OHMAN e 
FLORIDI, 2017) e (4) o comportamento de usuários e desenvolvedores frente aos SGDLs (MACIEL, 2011), (GULLOTA et al., 2016), (PEREIRA e PRATES, 2017)(PEREIRA et al., 2019).

Com base neste estudo que considerou três perspectivas de análise - a teórica, a sistêmica e a dos usuários, Yamauchi et al. (2021) perceberam que não há na literatura uma definição que contemple os SGLDs sob a perspectiva do objetivo primário dos sistemas que ofertarão esse serviço, isto é, se o foco recai no gerenciamento do legado, ou se se trata de funcionalidades embutidas em um sistema que possui outros fins. Assim, a pesquisa os classificou em (YAMAUCHI et al., 2021): a) Sistemas Integrados de Gerenciamento do Legado Digital (SIGLD) - aqueles que não possuem como um dos objetivos principais o gerenciamento do legado digital; e b) Sistemas Dedicados de Gerenciamento do Legado Digital (SDGLD) - os que possuem como objetivo principal o gerenciamento do legado digital. A principal diferença entre SDGLD e SIGLD é que os integrados não possuem como um dos objetivos principais o gerenciamento do legado digital. Estes sistemas apenas incorporam funcionalidades relacionadas ao legado digital para suprir outras necessidades. Portanto, são sistemas que continuam existindo mesmo se forem retiradas as funcionalidades de legado digital.

Quanto aos sistemas dedicados à administração do legado digital, existem algumas soluções Miigen (2021), Afternote (2021) e Meu Último Desejo (2021). Esses sistemas geralmente armazenam dados dos usuários em sistemas em nuvem gerando, entre outros problemas, a preocupação quanto às leis aplicadas nos territórios onde se localizam os servidores e a segurança na tramitação de dados. Em geral, esses sistemas possuem tratamento para dados de redes sociais, com distintas soluções, mais no sentido do armazenamento de credenciais e desejos póstumos. No Meu Último Desejo (2021), por exemplo, há a possibilidade de configurar um testamento patrimonial e outro vital.

Por sua vez, temos as soluções existentes no mercado para integração de funcionalidades de gerenciamento do legado à sistemas, como as do Facebook (2021), do Instagram (2021) e do Google Inactive Accounts (2021). De forma geral, são funcionalidades pré-configuradas em vida pelo usuário e executadas após a detecção de sua inatividade ou morte. Algumas envolvem a transferência de dados do usuário para terceiros, a transferência de uma conta, a transformação de perfil em memorial, ou a exclusão de seus respectivos dados/contas.

$\mathrm{O}$ respeito à vontade do usuário quanto ao destino de seus dados é tido por Maciel (2011) como um aspecto volitivo, um dos elementos da Web Social. O autor advoga que os softwares ofereçam opções de destinação de bens e ativos digitais de usuários falecidos, que sejam configuráveis em vida pelo proprietário da conta, e disponibilizem essa escolha desde a aceitação dos termos de uso, de forma clara e bem comunicada ao usuário. Ainda, cabe ressaltar que os serviços, sejam eles dedicados ou, principalmente integrados aos sistemas e redes sociais, devem considerar não somente $o$ desejo da preservação e do repasse dos bens, mas também a possibilidade da finitude "da vida" no mundo digital, por meio do apagamento dos dados.

Como pode-se perceber, tanto os SDGLD quanto os SIGLD tratam, de alguma forma, da relação entre as redes sociais e os bens digitais dos usuários a serem destinados à terceiros. Todavia, os sistemas que possuem as funcionalidades integradas, acabam por serem mais conhecidas pelos usuários. Isso se dá, muitas vezes, não pelo 
fato de o usuário saber como configurar dada rede social para ser ou não um memorial após a sua morte; mas pelo fato de os usuários perceberem que outros perfis acabam se transformando em memoriais na rede. Lopes et al. (2014) questionam como se dá a interação em torno de memoriais digitais, analisando os elementos que caracterizam redes sociais, vez que "formar redes de usuários "vivos" e "mortos" em um mesmo ambiente requer que sejam pensadas pelos projetistas da interação humano-computador e designers de software uma série de questões.". Todavia, é curioso observar os dados de uma rede social e pensar: a quem esses dados interessam após a morte do usuário? E, na profusão de dados que temos hoje em dia, quais destes dados são, de fato, úteis para compor o legado de uma pessoa? Estes dados, além de possível valor patrimonial, possuem valor emocional e importância para os processos de luto, ainda mais considerando o aspecto social da morte.

Pensando nos diferentes tipos de dados, Bahri et al. (2015) propõem um framework conceitual com vistas à administração de dados relacionados ao legado digital no contexto das redes sociais. O processo de definição do destino do legado digital é o ponto central, com várias etapas até a execução se concretizar. Para tal, os autores categorizam os dados contemplados pelo framework da seguinte forma: a) dados de doação: b) dados de legado, c) dados de propriedade intelectual, e d) dados destrutíveis, ou seja, os dados que o usuário deseja que sejam destruídos após sua morte.

Pesquisas com usuários tem apontado que a maior parte deles deseja ter seus dados apagados após sua morte, mas poucos deles já havia pensado sobre isso antes de serem abordados na pesquisa (GRIMM, CHIASSON, 2014) (CABRAL et al., 2021). Outros estudos, porém, afirmam que a exclusão de um perfil de uma rede social, tem forte impacto sobre o luto (TOLEDO et al., 2019), vez que eles dão suporte aos usuários enlutados possibilitando interação póstuma (MACIEL, PEREIRA, 2013). Cabe salientar que diferentes faixas de idade de usuários precisam ser estudadas neste campo, como a da Geração digital e Internet (MACIEL, PEREIRA, 2012)(CABRAL et al., 2021); os adultos (PEREIRA et al., 2019); e a terceira idade (VERHALEN et al., 2020).

Já Ohman e Floridi (2017), que discutem os serviços de SBLDs no contexto comercial, analisaram diferentes sistemas sob a ótica dos serviços oferecidos agrupandoos em quatro tipos: serviços de gerenciamento de informação, serviços de transmissão de mensagens póstumas, serviços de memorial online e serviços de recriação da vida. Estes serviços possibilitam muitas ações e reações nas redes sociais, sendo importante que a comunidade científica discuta as soluções e seus impactos junto com a indústria. Ainda, as redes sociais e suas características tem evoluído ao longo dos anos. Fato é que muito se avançou, do tempo em que tínhamos basicamente o Orkut (da SILVA, 2007) no Brasil, até hoje, com a maior conectividade dos usuários e inúmeras redes sociais. Todavia, no campo tecnológico, muitas questões têm se antecipado às leis.

\section{Da tecnologia à legislação}

Como em diversas discussões sistêmicas, os aspectos legais de dada aplicação têm forte impacto sobre a modelagem de software. Para tal, engenheiros de software tomam como base a legislação existente na área. Com relação ao tratamento da herança digital, no contexto do Brasil, não há legislação específica que regulamente a matéria. Projetos de Lei têm sido propostos nos últimos anos, tanto na Câmara dos Deputados quanto no Senado Federal, todavia apresentam soluções frágeis e que não tratam de todas as 
nuances dessa temática (BEPPU e MACIEL, 2020). Ainda, o "direito ao esquecimento" trouxe à baila discussões sobre a persistência de dados na Internet; contudo ele não trata necessariamente de pessoas falecidas.

Análises têm sido realizadas à luz do direito sucessório (MACIEL, PEREIRA, STEZM, 2015), do direito contratual (VIANA et al., 2020) e até dos direitos de personalidade (BEPPU e MACIEL, 2020). Para melhor organizar o ensaio, usamos essa divisão para abordar os assuntos, enfocando o sistema jurídico brasileiro.

\section{a) Direito Sucessório}

O direito sucessório, parte do direito civil, há variações de um país para o outro, especialmente no que tange a casos em que não há testamento (MACIEL, PEREIRA, STEZM, 2015). Isso se torna ainda mais complexo se considerarmos, no caso do legado digital, a dispersão global de usuários, empresas de software e servidores.

Atualmente, o Código Civil Brasileiro regulamenta a sucessão de direitos em seu artigo 1788 (BRASIL, 2002): "Art. 1.788. Morrendo a pessoa sem testamento, transmite a herança aos herdeiros legítimos; o mesmo ocorrerá quanto aos bens que não forem compreendidos no testamento; e subsiste a sucessão legítima se o testamento caducar, ou for julgado nulo". Em outras palavras, após o falecimento, na hipótese de o falecido não ter feito testamento ou, ainda que o tenha feito, caso determinado direito não tenha sido expressamente mencionado, esse direito se transmite aos herdeiros legítimos. É certo, portanto, que, se antes de falecer, determinada pessoa fizer um testamento, declarando expressamente sua vontade quanto a um direito, via de regra esta deve ser obedecida, a não ser que o testamento seja declarado nulo de pleno direito, ou então perca a validade.

Cabe reforçar que, em testamento, podem ser incluídos bens patrimoniais ou não. De forma geral, caso sejam bens monetizáveis, aplica-se o que prega o direito patrimonial e sucessório. Por sua vez, se o bem não tem valor econômico, em caso de falecimento do proprietário da conta, as cláusulas contratuais - em geral estabelecidas nos termos de uso em redes sociais - regem a tomada de decisão em caso de falecimento do proprietário da conta.

Autores tem advogado sobre o possível conflito entre o que rege um testamento e o que o usuário pode configurar em um sistema, no que tange a destinação dos bens digitais (MACIEL, 2011) (PEREIRA; PRATES, 2017). De toda sorte, se o usuário que falecer tiver designado um herdeiro em uma rede ou tiver repassado a senha para terceiros, que não seja aquele que teria direito via sucessão, e algum herdeiro da linha sucessória reivindicar, caberá ao Judiciário decidir o impasse, sendo certo que ainda não há entendimento pacificado sobre a questão. Quando o acesso é autorizado, pode até se dar a remoção dos perfis e conteúdos do falecido pelos herdeiros; todavia essa decisão é tomada uma vez que não está expressa a vontade do falecido em algum lugar. Neste caso, novamente, as cláusulas contratuais seriam analisadas.

No entanto, seguindo a lógica do direito sucessório, os conteúdos de contas e arquivos digitais devem ser transmitidos aos herdeiros, independentemente da vontade do proprietário dos dados. Ora, sob esta premissa, deixa-se de considerar a privacidade do falecido, bem como eventual desinteresse do mesmo, quando em vida, em ver suas contas acessadas após sua morte.

Em uma pesquisa, Maciel, Pereira e Sterm (2015), realizaram um estudo exploratório com uso de questionários, tendo como público-alvo engenheiros de software para Web. A partir de uma análise das respostas dos sujeitos de pesquisa, 
foram observados padrões temáticos agrupados em: a) direito sucessório; b) direito ao esquecimento; c) temporalidade das informações de contato; e d) impasses técnicos. Desse modo, a pesquisa tenciona essas questões, articulando aspectos culturais, técnicos e legais do destino do legado digital no Brasil.

Todavia, o repasse de bens digitais não é algo simples. Edwards e Harbinja (2014) elencam uma série de razões que dificultam o repasse desses bens: a) a dificuldade de definir o que são bens digitais; b) a dissensão entre os termos de uso de cada provedor de serviço e a legislação; c) a diferença de sistemas jurídicos entre as jurisdições onde mora o usuário falecido, onde mora o herdeiro, onde se localiza a sede da empresa de sofware e onde se localizam os provedores em que a informação está armazenada; d) os conflitos de interesses entre os stakeholders (usuário falecido, herdeiros e empresas de software); e) o respeito à privacidade do usuário falecido; e f) a dificuldade de separar o que é um bem digital (um e-mail, por exemplo) e o que é a informação que aquele bem digital carrega. Tais razões podem ser analisadas à luz dos direitos da personalidade, ou mais especificamente, no caso de pessoa falecida, do centro de interesses da personalidade.

No campo da privacidade e proteção, tem-se investigado a Lei Geral de Proteção de Dados Pessoais - LGPD (BRASIL, 2018), publicada em agosto de 2018 e que vigora desde setembro de 2020. A lei brasileira não trata de dados póstumos, a despeito de leis semelhantes em outros países. Todavia, Beppu e Maciel (2020) articulam caminhos possíveis para o tratamento de parte do legado digital (aquele de caráter não patrimonial) sob a perspectiva da LGPD, uma vez que essa lei é, hoje, a base do microssistema brasileiro de proteção de dados pessoais.

\section{a)Direito Contratual}

No que tange ao direito contratual, a perspectiva que tem sido trabalhada é a dos termos de uso e políticas de privacidade das aplicações. Entender como os termos de uso e as políticas de privacidade das redes sociais tratam a possibilidade de morte dos usuários é uma questão premente. Para entender como algumas redes sociais tratam a morte do usuário e realizar uma análise dos documentos que regem essas redes no Brasil, Viana et al. (2020) analisaram o Facebook, Pinterest, Instagram, Foursquare/Swarm, Linkedin, Whatsapp e YouTube. Na ocasião, percebeu-se que apenas YouTube e Facebook tinham disponíveis opções para repasse dos bens dos usuários para terceiros. Algumas redes sociais analisadas pelos autores tratam de particularidades quanto aos ativos ou bens digitais de usuário de modos diferentes, tratando-os de forma autônoma em suas políticas de privacidade. Os autores ressaltam que os agentes responsáveis para tratar das questões referentes às políticas de privacidade são as leis do estado da Califórnia (EUA), onde todas as redes sociais estabeleceram seus foros. Isso é um desafio para a implantação de termos de uso e políticas de privacidade, que podem não se identificar com as leis locais, como é o caso do Brasil. Isso porque, embora sediadas no estrangeiro, essas empresas coletam dados pessoais no território nacional, submetendose à lei brasileira. Nessa esteira, LGPD pode contribuir para a construção de um caminho normativo para a regulação do legado digital (BEPPU; MACIEL, 2020).

Exatamente pelo fato de não haver legislação específica sobre a questão, a regulamentação é casuística. Assim, por exemplo, no caso do Facebook, conforme consta nos Termos de Uso (VIANA et al., 2020), na hipótese de falecimento do usuário é necessário que a família ou um amigo envie a Certidão de Óbito do usuário para que a conta seja excluída. Nesse caso, a decisão de exclusão está nas mãos dos familiares, que 
"herdam" (por contrato) a possibilidade de destruir os dados, mesmo não tendo posse legal sobre os mesmos. Ainda, o usuário pode ter deixado um herdeiro cadastrado no Facebook, que terá determinadas permissões no perfil que se transformará em memorial do falecido. Neste sentido, cabe ressaltar que na ajuda do Facebook (2021), ao tratar da transformação dos perfis em memorial, consta "após o falecimento de uma pessoa, o Facebook respeita os desejos da mesma em relação ao que deve acontecer com sua conta". Ou seja, o aspecto volitivo da aplicação e de seu usuário é respeitado.

Se por um lado temos também a possibilidade de configuração da privacidade nos sistemas, em vida, é importante pontuar que essas decisões postas nos sistemas podem persistir após a morte do usuário, impondo outras restrições ao uso deste sem a presença do proprietário da conta, principalmente enquanto espaço de homenagem quando se trata de redes sociais.

\section{b) Direitos de Personalidade}

Com a ordem inaugurada via Constituição Federal de 1988, o campo do direito privado, que antes era considerado exclusivamente sob a ótica patrimonial, passa a centrar-se na pessoa humana. Segundo Beppu e Maciel, "ascendem, nesse contexto, o que se chamou de direitos de personalidade, que são aqueles "inerentes à condição humana" (ALMEIDA, 2019, p. 52). São exemplos de direitos da personalidade a privacidade, a intimidade, a honra e a imagem.”. Todavia, a implementação destes conceitos é desafiadora e interdisciplinar (BEPPU e MACIEL, 2020).

Conforme Leal (2018), não há sucessão de direitos da personalidade no Direito brasileiro, por serem personalíssimos, intransmissíveis ${ }^{1}$. O que há, na verdade, é a “[...] tutela de um centro de interesses relacionado à personalidade[...]", por compreender o aspecto existencial do falecido. Para Cadamuro (2015, p. 101), os direitos de personalidade materializam a memória do falecido. O Código Civil (BRASIL, 2002) trata do assunto no capítulo dos direitos da personalidade, conferindo legitimidade aos herdeiros do falecido para pleitear em juízo que cesse a ameaça ou lesão a direitos da personalidade, ou a reparação por ofensa a esses direitos ${ }^{2}$. Para Beppu e Maciel (2020), a partir desses pressupostos, torna-se possível definir os tipos de legado digital transmissíveis aos herdeiros, aqueles intransmissíveis e, os parâmetros para empresas desenvolvedoras de softwares e provedoras de aplicações gerirem o legado digital afeto ao campo de proteção da personalidade.

Em aplicações como, por exemplo, o Facebook, temos diferentes informações, desde fotos até reportagens. Neste caso, os dados existentes em uma conta de rede social são bens ou memórias digitais? A esse respeito, afirma Almeida $(2019$, p. 86) que: "por exemplo, fotos, nomes de domínio, mensagens, arquivos de documentos e blogs podem ser transmitidos a herdeiros, pois podem ter exploração econômica. Mas, por exemplo dados de localização, ou preferências de anúncios, não poderiam por representarem apenas faceta de personalidade, caso em que os herdeiros só teriam acesso caso houver disposição de última vontade nesse sentido."

Outra possibilidade mercadológica e em expansão é o uso da tecnologia blockchain, que permite registrar transações em uma arquitetura distribuída e descentralizada. Nestas, as criptomoedas são ativos digitais, mas não são os únicos (Alves et al., 2020). Bens como valor declarado são chamados de ativos digitais

\footnotetext{
${ }^{1}$ Art. 11, Código Civil Brasileiro (Lei no 10.406/2012).

${ }^{2}$ Art. 21, parágrafo único.
} 
(Oliveira et al, 2016). Recentemente, os Tokens Não Fungíveis (NFTs - Non-Fungible Tokens) têm atraído a atenção de investidores, com alguns NFTs garantindo considerados preços de venda (CHOHAN, 2021). Neste mercado, estão as cripto artes, representadas por obras de arte digital e até postagens de redes sociais. Essas discussões têm trazido novas possibilidades à discussão de legados digitais, uma vez que bens ou ativos digitais, como discutido, tem conotação patrimonial e econômica.

Em geral, no Brasil, o legado digital tem sido tratado unicamente sob a perspectiva da herança (direito sucessório), sem se atentar à complexa gama de situações afetas aos centros de interesse da personalidade do falecido, igualmente protegidos pelo ordenamento jurídico, ou da repercussão nos direitos de usuários vivos (BEPPU; MACIEL, 2020). Posto isso, creio que fica claro ao leitor os entraves para avançarmos nesta discussão e a necessidade premente de formulação de legislação específica para tratar todos os aspectos do legado digital.

\section{Considerações finais}

Apesar do tema estar em discussão a mais de uma década no Brasil e, no caso do projeto DAVI, ter pesquisadores de diversas instituições envolvidas, percebe-se que ele ainda tem muito a avançar. Situado no atual projeto do DAVI (2021), nomeado "Projeto de Sistemas Face ao Pré-gerenciamento do Legado Digital Pós--morte". O caminho trilhado neste ensaio focou os Sistemas Gerenciadores de Legado Digital numa perspectiva que vai dos aspectos tecnológicos aos legais, para desvelar ao leitor a complexidade do tema e problematizar ele no campo das redes sociais. Todavia, o longo dos últimos anos, para trilhar caminhos de pesquisa nesta área, tem-se buscado contribuir na conscientização e projeção das Tecnologias associadas ao Pós-morte, com estratégias que estão:

- questionando as soluções existentes, o custo destas aos usuários e as decisões que estão por trás das empresas;

- analisando as diferentes faixas de idade de usuários ou gerações que se relacionam e interagem com a tecnologia e seus posicionamentos, com vista a flexibilizar ou adaptar soluções e/ou trazer novas soluções;

- produzindo artefatos para a concepção de sistemas que considerem o destino do espólio digital via software e a geração de orientações, as quais servem também para organismos normativos discutirem tal temática. Apesar de as discussões estarem centradas nos requisitos funcionais, tem-se projetado artefatos com base em requisitos não-funcionais como usabilidade, comunicabilidade, interoperabilidade e segurança.

- investigando como SGLD têm sido desenvolvidos e qual a sua aceitação pelos usuários. Dado o espaço destes para expressão do luto, em especial nas redes sociais, os memoriais têm merecido a atenção.

- analisando a morte no contexto dos jogos, desde aspectos de tratam a herança neste campo até o desenvolvimento

- discutindo a imortalidade digital, vez que, por meio de nossos dados, é possível a "recriação da vida", ainda mais com os avanços da Inteligência Artificial. Neste ponto, as redes sociais têm muito a oferecer, todavia há implicações do uso destes dados.

- considerando os espaços do mundo real que tratam a morte, como cemitérios e locais 
ligados a serviços fúnebres, dado o potencial de design de sistemas associado à observação/análise destes espaços e a integração deles com os digitais/virtuais;

- variando os tipos de pesquisa, métodos, técnicas, ferramentas, com abordagens quantitativas e qualitativas; de forma a trazer diferentes olhares à temática.

- buscando vencer desafios relacionados à: discussão da temática, carregada de tabus e crenças sobre a morte que afetam usuários, desenvolvedores, academia e empresas de software; as questões associadas à ética em pesquisa, com ajustes especiais para o período da pandemia; à pesquisa interdisciplinar, em especial, pela discussão da morte ter que ser investigada considerando muitas facetas. Em especial, como tensionado neste ensaio, o campo do Direito, cujas análises têm sido realizadas à luz do direito sucessório, do direito contratual e dos direitos de personalidade.

- educando para a discussão da temática da morte: buscando a inserção da temática como desafios de pesquisa das comunidades brasileiras e produzindo textos para conferências, livros e divulgação científica; buscando integrar ensino, pesquisa e extensão; sensibilização desenvolvedores e usuários de tecnologias para a premência do tema, por meio das palestras com academia e mercado; divulgando o tema em redes sociais (Facebook e Intagram @dadosalemdavida); realizando estudos com estudantes sobre sua percepção quanto ao tema.

Essas diferentes estratégias podem ser exploradas via bibliografia com vistas a trabalhos futuros. Com relação às produções do projeto DAVI (2021), elas estão listadas em seu site. Os trabalhos do grupo têm olhar sobre a literatura internacional, todavia, com foco na cultura e leis do Brasil. Aos poucos, tem-se avançado, de forma interdisciplinar e com colaboração de diversas instituições, em especial, com profissionais das áreas de Computação, Design, Educação, Direito, Psicologia e Linguagens. Ao certo, neste fechamento, o campo do ensaio foi extrapolado. Todavia, foi intencional, uma vez que é mister lançar luz sobre as muitas implicações e possibilidades que os sistemas gerenciadores de legado digital trazem à pesquisa e ao desenvolvimento cientifico e tecnológico.

Por fim, reforça-se que, do ponto de vista legal, como ocorre em várias áreas, não só das sucessões, a legislação não acompanhou as mudanças da sociedade e, principalmente, o desenvolvimento da tecnologia. Ainda são necessários esforços no sentido de regulamentar a transmissão de bens imateriais. Desta forma e com ajuda de estudos interdisciplinares de possibilidades e limites neste campo, talvez seja possível avançar na discussão da temática como um todo.

\section{In memoriam}

Ao colega painelista do BraSNAM 2016, Artur Ziviani. Às vítimas da COVID-19.

\section{Agradecimentos}

As organizadoras do BraSNAM 2021, Jonice Oliveria e Mirella Moro, pela grande oportunidade de escrever este ensaio. Às advogadas com quem sigo apreendendo a faceta legal, Monica Sztern e Flavia Beppu. A todos/as que colaboram com o DAVI. Ao Conselho Nacional de Desenvolvimento Científico e Tecnológico - CNPq. 


\section{Referências}

AFTERNOTE. 2021. https://www.afternote.com/.

ALMEIDA. J.E. "Testamento digital: como se dá a sucessão dos bens digitais". Porto Alegre: Editora Fi, 2019.

ALVES, P.H. et al. Desmistificando blockchain: conceitos e aplicações. In: Cristiano Maciel; José Viterbo. (Org.). Computação e Sociedade: a Tecnologia - volume 3. 1ed. Cuiabá : EdUFMT - Editora da Universidade Federal de Mato Grosso, 2020, p. 166 - 197.ISBN:9786555880489

BAHRI, L., CARMINATI, B., FERRARI, E. What happens to my online social estate when I am gone? An integrated approach to posthumous online data management. In: 2015 IEEE International Conference on Information Reuse and Integration. IEEE, 2015. p. 31-38.

BEPPU, F., MACIEL, C. Perspectivas Normativas para o Legado Digital Pós-Morte Face à Lei Geral de Proteção de Dados Pessoais. In: Workshop Sobre as Implicações da Computação na Sociedade (WICS), 1. 2020, Cuiabá. Anais [...]. Porto Alegre: Sociedade Brasileira de Computação, 2020. p. 73-84.

BRASIL, Lei $n^{\circ}$ 13.709, de 14 de ago de 2018. "Lei Geral de Proteção de Dados Pessoais (LGPD)". Brasília: Presidência da República, [2018]. http://www.planalto.gov.br/ccivil_03/_ato2015-2018/2018/lei/113709.htm.

BRASIL. Lei $\mathrm{n}^{\mathrm{o}} 10.406$, de 10 de janeiro de 2002. Institui o Código Civil. Diário Oficial da União: seção 1, Brasília, DF, ano 139, n. 8, p. 1-74, 11 jan. 2002. http://www.planalto.gov.br/ccivil_03/leis/2002/110406compilada.htm

BRITTO, V. Artigos e ensaios científicos. RDE-Revista de Desenvolvimento Econômico, v. 3, n. 4, 2009.

CABRAL, J. M. et al. Digital Generation and Posthumous Interaction: A Descriptive Analysis in Social Networks. 2021. In: 23rd International Conference on Enterprise Information Systems (ICEIS), Online Streaming. 2021. p. 507-516.

CADAMURO, L. G. "A proteção dos direitos da personalidade e a herança digital". Centro Universitário Bauru: 2015.

CHOHAN, U.W. Non-Fungible Tokens: Blockchains, Scarcity, and Value (March 24, 2021). Critical Blockchain Research Initiative (CBRI) Working Papers, 2021,

da SILVA, A. L. M. A morte e os meios digitais de comunicação: uma análise dos rituais de luto no Orkut. End of term paper, Universidade do Vale do Rio dos Sinos, (São Leopoldo, Rio Grande do Sul, 2007), 86.

DAVI. Dados além da vida. 2021. https://lavi.ic.ufmt.br/davi/

DE OLIVEIRA, J. et al. A study on the need of digital heritage management plataforms. In: 2016 11th Iberian Conference on Information Systems and Technologies (CISTI). IEEE, Las Palmas, 2016. p. 1-6.

EDWARDS, L., HARBINJA. E. "What Happens to my Facebook Profile when I Die?": legal issues around transmission of digital assets on death. In: Maciel, C., Pereira, V.C. (eds.) Digital Legacy and Interaction: post mortem issues, pp. 115-144. Springer, London (2013) 
FACEBOOK. 2021. Transformação dos perfis em memorial no site do Facebook, opções de ajuda. https://www.facebook.com/help/requestmemorialization.

FARRUGIA, R. Post-Mortem data protection in the age of big data and its threat to personal autonomy. Thesis, Tilburg Institute for Law, Technology and Society, 113 pp (2014).

GOOGLE INACTIVE ACCOUNTS. 2021. https://myaccount.google.com/inactive

GRIMM, C., CHIASSON, S. Survey on the fate of digital footprints after death. In: Workshop on Usable Security (USEC), Internet Society. 2014.

GULOTTA, R. et al. Engaging with death online: An analysis of systems that support legacy-making, bereavement, and remembrance. In: Proceedings of the 2016 ACM Conference on Designing Interactive Systems. 2016. p. 736-748.

INSTAGRAN, 2018. "O que acontece quando a conta do Instagram de uma pessoa falecida é transformada em memorial?" https://help.instagram.com/231764660354188?helpref=faq_content

LARROSA, J. O ensaio e a escrita acadêmica. Educação \& Realidade, v. 28, n. 2, 2003.

LEAL, L.T. "Internet e morte do usuário: a necessária superação do paradigma da herança digital.” Revista Brasileira de Direito Civil RBDCilvil, Belo Horizonte: 2018.

LOPES, A. D.; PEREIRA, V. C.; MACIEL, C. Recomendações para o Design de Memórias Digitais na Web Social. In: 13th Brazilian Symposium on Human Factors in Computing Systems (IHC '14), Porto Alegre-RS, Brasil: SBC, 2014. p.275-284.

MACIEL, C. Issues of the Social Web interaction project faced with afterlife digital legacy. In: Proceedings of the 10th Brazilian Symposium on Human Factors in Computing Systems and the 5th Latin American Conference on Human-Computer Interaction. 2011. p. 3-12.

MACIEL, C., PEREIRA, V. C., PRATES, R., PEREIRA, F. H. S. Tecnologias associadas ao pós-morte. In: Cristiano Maciel; José Viterbo. (Org.). Computação e Sociedade: a Tecnologia - volume 3. 1ed.Cuiabá: EdUFMT - Editora da Universidade Federal de Mato Grosso, 2020, p. 224-258.

MACIEL, C., PEREIRA, V.C. (org.). Digital Legacy and Interaction: Post-Mortem Issues. Switzerland: Springer, 2013. 144p.

MACIEL, C., PEREIRA, V.C., SZTERN, M. Internet Users? Legal and Technical Perspectives on Digital Legacy Management for Post-mortem Interaction. In: 17th International Conference on Human-Computer Interaction (HCI 2015), 2015, Los Angeles. v. 9172. p. 627-639.

MACIEL, C.; PEREIRA, V.C. The internet generation and its representations of death: considerations for posthumous interaction projects. In: 11th Brazilian Symposium on Human Factors in Computing Systems (IHC '12). 2012, Porto Alegre-RS, Brasil : Brazilian Computer Society, 2012. p. 85-94.

MEU ÚLTIMO DESEJO. 2021. https://www.meuultimodesejo.com.br/.

MIIGEN. 2021. https://www.miigen.com/.

ÖHMAN, C., FLORIDI, L. The political economy of death in the age of information: A 
critical approach to the digital afterlife industry. Minds and Machines, v. 27, n. 4, p. 639-662, 2017.

PEREIRA, F.H.S. et al. Exploring Young Adults' Understanding and Experience with a Digital Legacy Management System. Journal on Interactive Systems, v. 10, n. 2, p. 50-69, 2019.

PEREIRA, F.H.S.; PRATES, R.O. A conceptual framework to design users digital legacy management systems. In: Proceedings of the XVI Brazilian Symposium on Human Factors in Computing Systems. 2017. p. 1-10.

SBC. Painel do $36^{\circ}$ Congresso da Sociedade Brasileira de Computação (CSBC) debate Legado Digital e privacidade. https://www.sbc.org.br/noticias/1856-painel-do-36congresso-da-sociedade-brasileira-de-computacao-csbc-debate-legado-digital-eprivacidade. 2016.

TREVISAN, D.; MACIEL, C. Morte, Educação e Tecnologias Digitais: Reflexões em tempos de Pandemia. SBC Horizontes, jul. 2020. ISSN 2175-9235. http://horizontes.sbc.org.br/index.php/2020/07/02/morte-educacao-e-tecnologiasdigitais

TOLEDO, T. et al. Identity and volition in Facebook digital memorials and the challenges of anticipating interaction. In: 18th Brazilian Symposium on Human Factors in Computing Systems - IHC '19, 2019, Vitória, n.31, p.1-11.

UEDA, G.S.; MACIEL, C.; VITERBO, J. Analysis of the Features of Online Tools in the Post-mortem Digital Legacy Domain. In: Anais do IX Workshop sobre Aspectos da Interação Humano-Computador para a Web Social. SBC, 2018. p. 001-012.

VERHALEN, A., MACIEL, C., DE SOUZA, P. Um Estudo Exploratório da Percepção de Idosos Sobre Bens e Legados Digitais. In: Workshop Sobre as Implicações da Computação na Sociedade (WICS), 1. Cuiabá. Anais [...]. Porto Alegre: Sociedade Brasileira de Computação, 2020. p.61-72.

VIANA, G. T. et al. Analysis of Terms of Use and Privacy Policies in Social Networks to Treat Users Death. In: SANTOS, R. P. dos; MACIEL, C.; VITERBO, J. (org.). Communications in Computer and Information Science. Switzerland : Springer International Publishing, 2020. v.1081, p. 60-78.

YAMAUCHI, E. A. et al. Digital Legacy Management Systems: Theoretical, Systemic and User's Perspective. 2021. In: 23rd International Conference on Enterprise Information Systems (ICEIS), Online Streaming. 2021. p. 41-53.

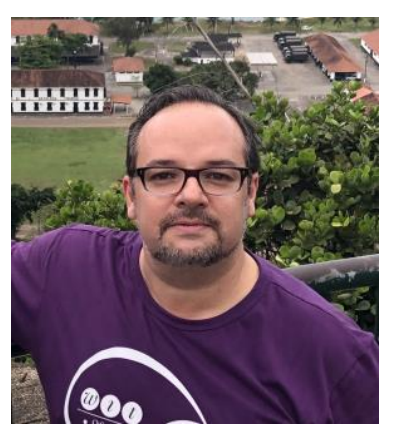

Cristiano Maciel. Doutor em Ciência da Computação pela Universidade Federal Fluminense, professor da Universidade Federal de Mato Grosso. Membro da Sociedade Brasileira de Computação. Tem interesse em interação humano-computador, engenharia de software, redes sociais, governo eletrônico, legado digital pós-morte e tecnologias na educação. É autor de livro e artigos na área de legado digital pós-morte e coordenador do projeto Dados Além da Vida - DAVI: https://lavi.ic.ufmt.br/davi/. Link para o Lattes: http://lattes.cnpq.br/5234437367053668 